\title{
Mentoring at Tertiary Level Education: A Tool to Exceed Students' Problems
}

\section{OPEN ACCESS}

Volume: 7

Issue: 4

Month: September

Year: 2019

P-ISSN: 2320-2645

Received: 01.08.2019

Accepted: 19.08 .2019

Published: 01.09.2019

Citation:

Suchana, Afroza Aziz.

"Mentoring at Tertiary

Level Education: A Tool

to Exceed Students'

Problems." Shanlax

International Journal

of English, vol. 7, no. 4, 2019, pp. 11-17.

DOI:

https://doi.org/10.34293/

english.v7i4.620

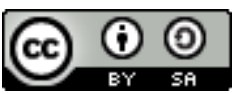

This work is licensed under a Creative Commons AttributionShareAlike 4.0 International License

\section{Afroza Aziz Suchana}

Assistant Professor, Department of English, University of Asia Pacific, Dhaka, Bangladesh

\begin{abstract}
The study examines the role of mentoring to surpass the problems of tertiary level students. It includes both mentors' and mentees' views on mentoring. It explores how mentoring helps the mentor find out students' problems and to provide them with emotional and instrumental support. Adapting the qualitative method, this research includes case studies of three different students of a private university of Bangladesh who had been facing various problems and shows how they overcame their obstacles. It exposes the difficulties and challenges of one fresher, one female and one minority student. The study applies both formal and informal aspects of mentoring. It also includes an interview of their mentors. Findings indicate that through this process, mentors may find students' problems and help them go over and inspire them with a vision of the future. The study finds that mentoring contributes to students' academic achievement and social integration. It also states that through mentoring students' frustration can be transformed into motivation.
\end{abstract}

Keywords: Mentor, Mentoring, Protégé, Academic success, Social integration.

\section{Introduction}

Despite the significance of the mentoring, the absence of a consistent definition has been recognized by the researchers. Jacobi (1991) finds the absence of a widely accepted operational definition of mentoring. Other researchers also have expressed frustration at the lack of definitional clarity surrounding the mentor concept (Merriam, 1983; Speizer 1981). However, Clark, Harden and Johnson (2000) define mentoring as a personal relationship in which a more experienced (usually older) individual acts as a guide, role model, teacher, and sponsor of a less experienced (usually younger) protégé. Kram (1985) refers to the origin of the term mentoring. "Derived from Greek methodology, the name implies a relationship between a young adult and an older, more experienced adult that helps the younger individual learn to navigate in the adult world and the world of work. A mentor supports, guides, and counsels the young adult as he/she accomplishes this important task" (Kram, 1985.p.2). Lester and Johnson (1981) define mentoring as "a one-to-one learning relationship between an older person and a younger person that is based on modelling behavior and extended dialogue between them." (p.119).

Fagenson (1989) defines a mentor as "someone in a position of power who looks out for you, or gives you advice, or brings your accomplishments to the attention of other people who have power in the company" (p.312). This study brings out mentoring as a faculty activity where the faculty members solve various problems of the student mentees through proper guidance.

\section{Types of Mentoring}

Mentors develop their relationship with mentees in various forms. Wallace, Abel and Ropers-Huilman (2000) mention that mentoring relationships can develop either informally or formally. 
Formal mentoring is a systematic and structured process. Informal relationships develop through student interaction with faculty, staff, peers, or others. These informal relationships develop students' scholarly potential. They also emphasize the benefits of formal mentoring. While revealing the link between mentoring and academic success, Jacobi (1991) also mentioned formal and informal mentoring. This study also traces both formal and informal mentoring.

\section{Formal Mentoring}

The study includes a structured and intentional approach to look into the students' problems. Such initiatives are often facilitated by institutions. Jacobi (1991) finds the popularity of the formal mentoring program. Such programs have been designed for a range of issues including career development, leadership development and students' academic success. But such programs may have some limitations. One of the problems is diversity. "Mentoring programs may use faculty, staff, administrators, or students as mentors; the mentor and protégée may meet in individual or group settings; meetings may occur in the residence hall setting, classroom setting, or elsewhere." (Jacobi, 1991). Diversity is also found in the frequency of meeting, goals, objectives and outcomes.

This research observes mentoring program of a private university of Bangladesh which offers a formal mentoring session for the students. Here, teachers formally meet his/her mentees twice a week. They follow structured mentoring forms to note down students' progress.

\section{Informal Mentoring}

It refers to naturally occurring mentoring. Sometimes, the teacher notices a lack of attention or confidence through the behaviour or facial expression of the students. But in front of the whole class, they do not want to expose their problems. Teachers sometimes realize that as the proficiency level of all learners is not equal, some students need extra care beside the class. In that case, the mentors manage some extra hours for those students in an informal setting where the mentees may feel free to share their problems. By this way, a mentor may trace the problems and offer solutions to the mentees.

Existing research studies find the diverse outcome of naturally occurring mentoring. "Only one study could be found that directly assessed the relationship between natural mentoring and academic success among undergraduates." (Jacobi, 1991). Some other studies find a positive outcome of such mentoring programs.

\section{Research Questions}

In my research, I intend to explore the research questions given below:

To what extent mentoring can solve mentees' problems?

How is mentoring viewed by the students?

How is mentoring viewed by the mentor?

\section{Literature Review}

Mentorship is a widely regarded phenomenon for undergraduate students, but there is a lack of literature on this issue. However, the value of mentoring has long been traced by the researchers. Zey (1984) notices an increased awareness of mentoring. He finds that in the last few years, the concept of the "mentor" has become a part of the common practice. He mentions by the mid-1980s, interest in the field had grown to the people. Hence, researchers and practitioners started holding conferences and meetings on mentoring. "One of the earliest was the 1986 International conference on Mentoring. In the 1980 s a variety of mentoring organizations emerged in different parts of the U.S. and Canada. The International Mentoring Association, based at Western Michigan University, is one of the most active, combining the efforts of educators, business people, practitioners, and professionals to study this subject and perhaps foster mentoring activities" (Zey, 1984).

In Bangladesh, some universities have already started mentoring programs for undergraduate students. In these universities, faculty members act as mentors of some students. Jacobi (1991) finds a link between mentoring and academic success. A mentor provides academic advice, and at the same time, a mentee may share personal problems with his/her mentor. Advice and guidance can make a mentee motivated and confident. Jacobi 
(1991) conducted an in-depth literature review on mentoring undergraduate students and identified some fundamental components of mentoring. These are -

Mentoring relationships are helping relationships usually focused on achievement. The primary dynamic of the mentoring relationship is the assistance and support provided to the protégé by the mentor.

\section{Mentoring includes any or all of three broad components:}

Emotional and psychological support;

Direct assistance with career and professional development; and

Role modeling.

Mentoring relationships are reciprocal.

Mentoring relationships are personal.

Relative to their protégés, mentors show greater experience, influence, and achievement within a particular organization or environment. (p. 513).

Research studies show that teachers, particularly professors, play a substantial role as mentors to their students (Busch, 1985; Cameron \& Blackburn, 1981; Wilde and Schau; 1991). Many graduate and undergraduate psychology programs now use the term mentoring to describe the sort of relationship they believe frequently exists or that they hope to foster between students and faculty. Promotional brochures may contain statements such as your students enjoy close mentoring relationships with faculty (Koch and Johnson, 2000).

However, some researchers do not find mentoring as a highly efficient way of achieving success. Existing empirical research studies also note some limitations and challenges of the mentoring program. Issues like gender or ethnic differences in mentoring are not addressed in many studies. Jacobi (1991) suggests more focused research about the possible interactive or mediating effects of sex and ethnicity on the development and outcomes of mentoring relationships in higher education.

These research studies provide a rationale for the current study. The present study traces whether and how mentoring programs help undergraduate students in the context of Bangladesh.

\section{Theoretical Construct}

A variety of broad theoretical explanations have been provided by different researchers. This research traces the theoretical framework proposed by Hunt and Michael (1983). They present a comprehensive framework for research on mentoring. A critical dimension of this framework includes the following categories:

Contextual factors for mentor-protégé relationship

Gender and characteristics of the role partners

The stages of the relationship

The positive and negative outcomes are accruing to the mentor, to the protégé, and their organization. (Hunt and Michael, 1983).

This study analyses the contextual or environmental factors of the mentor-protégé relationship. It deals with both male and female mentees. The study comprises both formal and informal relationship between the mentors and mentees. It also assesses the outcomes for mentor, protégé, and organisation.

\section{Methodology}

This research adapts the qualitative method. This method focuses on describing, understanding, and clarifying a human experience, and therefore, qualitative studies are directed at describing the aspects that make up an idiosyncratic experience (Polkinghorne 2005). Jacobi (1991) mentions that qualitative methods have much to contribute to a better understanding of the relationship between mentoring and academic success. This study examines three students' experiences of their involvement with formal mentoring programs. It also looks at students' experience of getting assistance from their mentors through informal mentoring. They are the undergraduate students of a private university. Their views and opinions have been traced through case studies. Cases are primarily people, but researchers can also explore in-depth a programme, an institution, an organization, or a community. Almost anything can serve as a case as long as it constitutes a single entity with clearly defined boundaries. (Dornyei, 2007).

The study includes interviews and observation as data collection methods, as Dornyei (2007) mentions 
that case study researchers usually combine a variety of data collection methods such as interviews, observation and document archives. Along with three students, it also takes interview of the mentors of them.

\section{Data analysis and interpretation}

This study explores how a teacher can trace students' problems and help them exceed. It reveals a mentor-protégé relationship both inside and outside the classroom. As the proficiency level of all learners is not equal, some students need extra care beside the class.

This study selects three mentees of diversified background. The first mentee is a female student; the second one is a newly admitted student, and the third one is an ethnic student of a private university. Their cases have been analyzed by the researchers. The findings are presented below:

\section{Case Study 1}

A female student came to her mentor who is the direct teacher of her and informed that her friends completed their studies, but she could not, and she was very upset and frustrated. The mentor made one to one interaction with her came to know that she was struggling as her husband left her. And she had a child, and she was able to manage a job also, but without achieving her honours degree, she cannot be successful. She was eager to study, but it was not possible for her to attend classes. The mentor realized her problem; it affected her. Then she talked to her (the mentee) and asked her desire. Both the mentor and the mentee discussed, and finally, they made a way out. The mentor suggested some books for her and provided materials. She studied at home, and whenever she faced any difficulty, she went to her mentor. And the mentor also told her to feel free to call her and talked over the phone. There were some new teachers in the department with whom she had some courses, but she couldn't express her problems. On behalf of her, the mentor talked to them and wanted cooperation from them. Finally, she completed her honours and till now she is in touch with her mentor. Now the mentee is doing a government job.

\section{The Protégé's View}

For this research, the researcher has taken the protégé's interview, and the protégé shared her experience. Time and again, she expressed her gratitude towards her mentor. She received both formal and informal mentoring. She mentioned that mentoring helped her shape up her life. By analyzing her case, the researcher has found the answer to research question 1 and 2 .

\section{Case Study 2}

Here, the mentee is a newly admitted student who attended the formal mentoring session with her mentor. She shared her problem to the mentor that she was very nervous. She was very weak in grammar and pronunciation. She had a lack of confidence. The mentor conducted a meticulous conversation with her and realized that she needed some extra care. Then the mentor conducted informal mentoring with the mentee. The mentor always inspired and motivated her. He suggested books to practice some grammatical activities and gave her at least one passage to read out loudly. And he always encouraged her by saying "You can do". Then the mentor noticed a difference in her performance. She was improving, and gradually, she became more confident.

\section{The Student's View}

In the interview session, the mentee acknowledged that mentoring helped her a lot. Through mentoring, she became confident and enthusiastic. This also provides the answer with research question 1 and 2.

\section{Case Study 3}

This case finds a male ethnic student as a mentee. From the very beginning of his university life, he had been facing some challenges, especially with his language. His first language was his ethnic language; he had to use Bangla with his friends and others and English in the classroom. He faced tremendous peer pressure to improve his language skill. Sometimes, they mocked at him. His mentor helped him overcome the problem through formal and informal mentoring. For the mentor it was also challenging to manage the diversified classroom as that tribal student did not understand English even Bengali 
properly. The mentor talked more to him and also provided some guidelines for him. The mentee felt motivated, and gradually, he coped up with his peers. Slowly, the teacher noticed that in presentation sessions that tribal student made better performance than his friends. The mentor also noticed confidence in the protégé.

\section{The Mentee's View}

The student mentee here expressed a highly positive view regarding mentoring. He mentioned that the mentor helped him out with his weaknesses and utilized his strengths. He added that mentoring improved his skills and confidence, as well. This study also provided answers to the research questions 1 and 2.

While dealing with the cases of the above three students, the researcher asked the following closeended questions to them -

How do you feel about mentoring? a) necessary b) unnecessary

What is your experience with it? a) found it helpful b) it didn't help me

Did you get the help from your mentor what you needed? a) yes b) no

Did mentoring improve your performance as a student? a) yes b) no

Is your mentor helping you in achieving what you want to do/be in your life? a) yes b) no

And all the three students answered positively. All of them viewed mentoring as a necessary tool for development. They found the process very helpful. They mentioned that they always got help from their mentors. They noted that mentoring improved their performances as students and helped them fix their goals and visions.

\section{The Mentors' View}

Semi-structured interview of the mentors of those three students has been taken. The mentors conduct both formal and informal mentoring. Every week they sit with their mentees in the formal mentoring sessions, but they find that it is not an easy task to trace students' problems. They come across that some students are not even aware of their problems, especially the newly admitted students. Having friendly discussions with them, the mentors mark out several issues and talk about the ways to overcome. They also ask for suggestions from the mentees themselves.

They point out that they focus on different aspects while conducting both formal and informal mentoring. These are:

- Academic activities

- Administrative activities

- Social and co-curricular activities

- Personal problems and potentials

\section{Educational Activities}

The mentors discuss classes, results and attendance in the regular formal sessions. They keep a record of the mentees' results of different semesters and continuously monitor their progress. If they notice any drawback or downfall, they try to find out the reasons. They give extra time to the mentees and help them overcome. If the students continuously miss the class, the mentors call them and sometimes talk to their guardians to know and solve the difficulties. The mentors view mentoring as an effective endeavour in this regard.

\section{Administrative Activities}

One of the mentors found grievances in her mentees against the administrative operations of the university. Her mentees found problems while paying their tuition fees. The students complained that they had to pay late fine. They claimed that they were giving the payment on time. Then, the mentor examined and found that her mentees did not follow the academic calendar. Those students were not aware of the deadline. Administrative officers were not able to clarify the academic calendar to them.

\section{Social and Co-Curricular Activities}

The mentors mentioned that along with academic performances, they always encouraged their protégés to be actively involved in social and co-curricular activities. One of the mentors highlighted four features of mentoring sessions. These are - social integration, mutual support, group identity and friendship. This mentor viewed social integration as a dynamic process. He found that for the betterment of the students as well as the university, social inclusion is needed. Therefore, he suggested his 
mentees to build a friendly relationship with the senior and junior students of the university. All three mentors focused on mutual support and advised their mentees to achieve the skill of assimilation.

\section{Personal Problems and Potentials}

During the interview sessions, all the mentors mentioned that they emphasised mentees' affective domains. They exchanged views with their mentees regarding their problems, preferences, weaknesses, future career plans, etc. The mentors nurtured the leadership qualities among the mentees. Consequently, they noticed confidence in their mentees.

Thus, it is found that mentors view mentoring an insightful process where the protégés get direct support from their mentors. If the mentors can trace mentees' problems and potentials, students may overcome those problems and turn out to be confident. The mentors' experience and opinion provide the researcher with the answer to research question 3.

\section{Findings}

Adapting Hunt and Michael's (1983) framework, the study investigates mentors - mentees relationship at higher education in the context of Bangladesh. It pinpoints mentoring as an effective way to trace and surpass students' problems.

Both the mentors and the mentees viewed mentoring as a useful tool. The mentors mentioned that they believe that mentoring can enhance students' academic performance as well as personal development. The mentors emphasised the significance of both formal and informal mentoring. Duration of the mentoring relationship varied in formal and informal sessions. In the formal mentoring sessions, the mentors met the students at a particular time. The mentors mentioned that usually in the formal sessions, they focused on academic and administrative problems of the protégés. They also noticed that sometimes the students became introverted and could not share their problems in the formal sessions, which often led to frustration. Therefore, the mentors found the necessity of informal mentoring. They found interaction in an intimate setting can make a closer relationship among the mentors and the protégés.
This study revealed that by using both formal and informal mentoring, the mentors dealt with the problems of diversified students, including a female, a newly admitted and a tribal student. The mentors of the female and the tribal students expose the gender and ethnicity effects on mentoring. The study revealed mentoring as a useful tool to exceed the problems both a male and a female student. At the same time, it showed the academic success of an ethnic student.

Besides academic and administrative support, the mentors also gave guidance and emotional support to the mentees. Similarly, the mentees also found the mentors as trusted advisors. They found mentoring as a helpful and necessary tool. They believe that having a mentor leads to success.

\section{Conclusion}

The study evaluated the impact of mentoring on students' academic, personal and social developments. It revealed mentoring as an effective tool to identify and exceed students' problems. Therefore, it found that successful mentoring may contribute to students' academic success. It also traced the impact of mentoring on the development of mentees' social integration ability. The mentees shared their goals and fears openly. They also shared where they were struggling and failing. The mentors listened to their problems, expectations and goals carefully and provided them with guidelines and support. The mentees valued their mentors' support and felt motivated and inspired. Thus, the study exposed mentoring as a valuable strategy to increase motivation and confidence among the students.

\section{References}

Busch, J.W. "Mentoring in Graduate Schools of Education: Mentors' Perceptions." American Educational Research Journal, vol. 22, no. 1, 1985, pp. 257-265.

Cameron, S.W and Blackburn, R.T. "Sponsorship and academic career success." Journal of Higher Education, vol. 52, no. 1, 1981, pp. 369-377.

Clark, R.A, Harden, S.L and Johnson, W.B. "Mentor Relationships in Clinical Psychology Doctoral Training: Results of a National Survey." Teaching of Psychology, vol. 27, no. 4, 2000, pp. 262-268. 
Dörnyei, Z. Research Methods in Applied Linguistics: Quantitative, Qualitative and Mixed Methodologies, Oxford University Press, Oxford, 2007.

Fagenson, E.A. "The Mentor Advantage: Perceived Career/Job Experiences of Protégés Versus Non-Protégés." Journal of Organizational Behavior, vol. 10, no. 4, 1989, pp. 309-320.

Hunt, D.M and Michael, C. "Mentorship: A Career Training and Development Tool." Academy of management Review, vol. 8, no. 3, 1983, pp. 475-485.

Jacobi, M. "Mentoring and Undergraduate Academic Success: A Literature Review." Review of Educational Research, vol. 61, no. 1, 1991, pp. 505-532.

Koch, C and Johnson, W.B. "Documenting the Benefits of Undergraduate Mentoring." Council on Undergraduate Research Quarterly, vol. 20, no. 4, 2000, pp. 172-175.

Kram, K.E. Mentoring at Work: Developmental Relationships in Organizational life, Scott, foresman \& Co, Glenview, 1985.

Lester, V and Johnson, C. "The Learning Dialogue:
Mentoring." New Directions for Student Services, vol. 1981, no. 15, 1981 pp. 49-56.

Meriam, M. "Mentors and Proteges: A Critical Review of the Literature." Adult Education Quarterly, vol. 33, no. 1, 1983, pp. 161-173.

Polkinghorne, D.E. "Language and Meaning: Data Collection in Qualitative Research." Journal of Counseling Psychology, vol. 52, no. 2, 2005, pp. 137-145.

Speizer, J.J. "Role Models, Mentors and Sponsors: The Elusive Concepts." Journal of Women in Culture and Society, vol. 6, no. 1, 1981, pp. 692-712.

Wallace, D, Abel, R and Ropers-Huilman, B. "Clearing a Path for Success: Deconstructing Borders through Undergraduate Mentoring." The Review of Higher Education, vol. 24, no. 1, 2000, pp. 87-102.

Wilde, J.B and Schau, C.G. "Mentoring in Graduate Schools of Education: Mentees' Perception." Journal of Experimental Education, vol. 59, no. 1, 1991, pp. 165-179.

Zey, M.G. The Mentor Connection, Irwin Professional Publishing, 1984.

\section{Author Details}

Afroza Aziz Suchana, Assistant Professor, Department of English, University of Asia Pacific, Dhaka, Bangladesh,

Email ID: suchanadu@gmail.com. 